\title{
Study on influence factors of laser welding crack sensitivity of austenite stainless steel
}

\author{
Zhu Haiyan, Qin Ming, Zhang Xudong \\ Production Technology Research Dept. \\ Hitachi (China) Research \& Development Corporation \\ Shanghai, China \\ hyzhu@hitachi.cn
}

\begin{abstract}
Investigation on the influence of chemical composition on the precipitation of $\delta$-ferrite phase during solidification process with simulation method has been done in this study. Meanwhile, Fan-shaped laser beam welding method was used to verify the reliability of simulation results. The research results are shown as follows: increase of $\mathrm{C}, \mathrm{Ni} \& \mathrm{~N}$ will lead to $\delta$-ferrite content decrease, increase of $\mathrm{Cr}$ will lead to $\delta$-ferrite content increase, while $S i \& M n$ show different from the other elements, with increasing of $\mathrm{Si} \& \mathrm{Mn}$ content, $\delta$-ferrite increases first and then decreases. As we know, with the increase of $\mathrm{Creq} / \mathrm{Nieq}$, the content of $\boldsymbol{\delta}$-ferrite will increase, the welding crack sensitivity will decrease. Therefore, according to above mentioned results, lower $\mathrm{C}, \mathrm{Ni}$, and $\mathrm{N}$, higher $\mathrm{Cr}$, and suitable $\mathrm{Mn}$ and $\mathrm{Si}$ will be helpful to reduce the laser welding crack sensitivity of austenite stainless steel.
\end{abstract}

Keywords—laser welding; welding crack sensitivity; simulation

\section{INTRODUCTION}

One of the main defects of austenitic stainless steel laser welding is thermal cracking, because the thermal conductivity of austenitic stainless steel is low, while line expansion coefficient is large, which lead to a large shrinkage deformation and tensile stress during solidification process after welding, and result in solidification cracks. Another reason for solidification cracking is that the austenite has low solubility to impurities, the eutectic elements $(\mathrm{S}, \mathrm{P}, \mathrm{Si}, \mathrm{Nb})$ with low melting point tend to segregate along the columnar crystals and dendrites, and form low melting eutectic liquid films, which will susceptible to the shrinkage and tensile stress when crystallization is completed, the cracking will occur along the crystal boundaries.

In order to reduce the tendency of thermal cracking, it would be better to contain some $\delta$-ferrite in the the welding structure. During the solidification process, the amount of $\delta$-ferrite in the austenitic stainless steel can be obtained according to the $\mathrm{Cr}$ equivalent of the austenite forming element and the $\mathrm{Ni}$ equivalent of the ferrite forming element in the chemical composition by simulation. However, due to the differente solidification conditions, the amount of $\delta$-ferrite will be different accordingly.

The elements of stainless steel can be divided into ferrite former elements and austenite former elements, different elements ratio will lead to different $\delta$-ferrite content. In this paper, we will investigate the influence of chemical composition on the precipitation of $\delta$-ferrite phase during solidification process by thermo-Calc simulation software .

\section{INVESTIGATION PROCEDURE}

\section{A. Simulation Procedure}

This paper focuses on investigating the influence of chemical composition on the precipitation of $\delta$-ferrite phase during solidification process with simulation method. Thermo-Calc simulation software can't define cooling rate, it can only simulate equilibrium state solidification process. Actually, the cooling rate of welding process is about $700^{\circ} \mathrm{C} / \mathrm{s}$ to $1000^{\circ} \mathrm{C} / \mathrm{s}$. While we can use simulation result as a reference.

TABLE I. 24 DIFFERENT COMBINATIONS OF 6 ELEMENTS

\begin{tabular}{|c|c|c|c|c|c|c|c|}
\hline Elements & $\mathbf{C}$ & $\mathbf{S i}$ & Mn & $\mathbf{N i}$ & $\mathrm{Cr}$ & $\mathbf{N}$ & $\mathrm{Fe}$ \\
\hline 1 & 0.07 & 1 & 2 & 10 & 19 & 0.1 & Rest \\
\hline 2 & 0.07 & 1 & 1.5 & 9 & 18 & 0.05 & Rest \\
\hline 3 & 0.07 & 0.6 & 1 & 8 & 17 & 0.01 & Rest \\
\hline 4 & 0.07 & 0.6 & 1 & 8 & 18 & 0.1 & Rest \\
\hline 5 & 0.07 & 0.2 & 2 & 9 & 17 & 0.05 & Rest \\
\hline 6 & 0.07 & 0.2 & 1.5 & 10 & 19 & 0.01 & Rest \\
\hline 7 & 0.04 & 1 & 1.5 & 10 & 17 & 0.1 & Rest \\
\hline 8 & 0.04 & 1 & 1 & 9 & 19 & 0.05 & Rest \\
\hline 9 & 0.04 & 0.6 & 2 & 8 & 18 & 0.01 & Rest \\
\hline 10 & 0.04 & 0.6 & 2 & 8 & 19 & 0.1 & Rest \\
\hline 11 & 0.04 & 0.2 & 1.5 & 9 & 18 & 0.05 & Rest \\
\hline 12 & 0.04 & 0.2 & 1 & 10 & 17 & 0.01 & Rest \\
\hline 13 & 0.01 & 1 & 1 & 10 & 18 & 0.1 & Rest \\
\hline 14 & 0.01 & 1 & 2 & 9 & 17 & 0.05 & Rest \\
\hline 15 & 0.01 & 0.6 & 1.5 & 8 & 19 & 0.01 & Rest \\
\hline 16 & 0.01 & 0.6 & 1.5 & 8 & 17 & 0.1 & Rest \\
\hline 17 & 0.01 & 0.2 & 1 & 9 & 19 & 0.05 & Rest \\
\hline 18 & 0.01 & 0.2 & 2 & 10 & 18 & 0.01 & Rest \\
\hline 19 & 0.07 & 1 & 2 & 10 & 19 & 0.5 & Rest \\
\hline 20 & 0.07 & 0.6 & 1 & 8 & 18 & 0.5 & Rest \\
\hline 21 & 0.04 & 1 & 1.5 & 10 & 17 & 0.5 & Rest \\
\hline 22 & 0.04 & 0.6 & 2 & 8 & 19 & 0.5 & Rest \\
\hline 23 & 0.01 & 1 & 1 & 10 & 18 & 0.5 & Rest \\
\hline 24 & 0.01 & 0.6 & 1.5 & 8 & 17 & 0.5 & Rest \\
\hline
\end{tabular}


We designed 24 different combinations of 6 elements $(\mathrm{C}, \mathrm{N}$, $\mathrm{Cr}, \mathrm{Ni}, \mathrm{Si}, \mathrm{Mn}$ ) based on Chinese GB for SUS304 (Table I). We selected the upper limit, lower limit and median value of every element and combined them by orthogonal method, at last we got 18 different combinations.

For element N, there is no definition in the GB, we chose lower limit 0.01 , upper limit 0.1 . While during laser welding, usually $\mathrm{N}$ is chosen as shielding gas, we add 0.5 as another upper limit. Totally we got 24 different combinations of 6 elements.

\section{B. Experimental Procedure}

Fan-shaped laser beam welding [1] method will be used to verify the reliability of the simulation results. As shown in Fig. 1 is the sketch map of the experiment. The weld bead locates at the side of the plate, the situation results in very large constraint stress at B area as the limited deformability of it. $\Theta$ represents the different of the width of B area between Start and End. 'Ws' is the width of start area B part corresponding to constraint intensity.

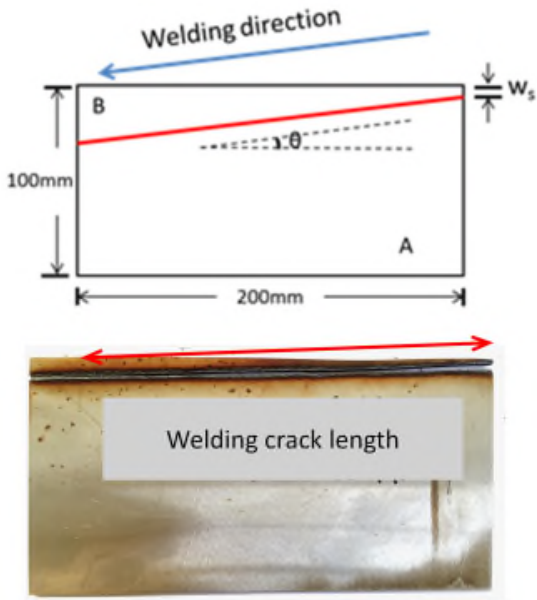

Fig. 1. Sketch map of the Fan-shaped method

We choose $4 \mathrm{~kW}-1.5 \mathrm{~m} / \mathrm{min}-2^{\circ}$ as parameter of the experiment, all experiments are zero defocusing with $0.40 \mathrm{~mm}$ beam spot. And we choose Ar as the shielding gas.

TABLE II. CHEMICAL COMPOSITIONS OF VERIFICATION MATERIALS

\begin{tabular}{|c|c|c|c|c|c|c|c|c|c|}
\hline Company & $\mathbf{C}$ & $\mathbf{S i}$ & $\mathbf{M n}$ & $\mathbf{P}$ & $\mathbf{S}$ & $\mathbf{N i}$ & $\mathbf{C r}$ & $\mathbf{N}$ & $\mathbf{A l}$ \\
\hline A & 0.008 & 0.75 & 1.23 & 0.039 & 0.018 & 8.33 & 18.13 & 0.06 & 0.01 \\
\hline B & 0.008 & 0.75 & 1.23 & 0.037 & 0.018 & 8.29 & 18.08 & 0.06 & 0.01 \\
\hline C & 0.065 & 0.63 & 1.04 & & 0.0031 & 4.59 & 16.07 & 0.032 & - \\
\hline D & 0.03 & 0.41 & 1.03 & 0.031 & 0.002 & 4.86 & 16.27 & 0.03 & - \\
\hline & $\mathbf{V}$ & $\mathbf{T i}$ & $\mathbf{W}$ & $\mathbf{N b}$ & $\mathbf{S n}$ & $\mathbf{Z n}$ & $\mathbf{O}$ & $\mathbf{F e}$ \\
\hline A & 0.08 & 0.01 & 0.01 & 0.01 & 0.01 & 0.01 & 0.018 & 71.277 \\
\hline B & 0.08 & 0.01 & 0.01 & 0.01 & 0.01 & 0.01 & 0.015 & 71.372 \\
\hline C & - & 0.0085 & - & - & - & - & - & 76.3444 \\
\hline D & - & - & - & - & - & - & - & 76.257 \\
\hline
\end{tabular}

Four materials were selected to verify the reliability of simulation results in this research, such as SUS304 made by company A and B, and DIN1.4418 made by company C and D. The chemical compositions refer to Table II. The average length of the crack with each parameter were summarized to find the relationship between chemical elements and cracks.

\section{RESULTS}

\section{A. Simulation Results}

Fig. 2 shows relationship between different elements and $\delta$-ferrite content. From the results, it is found that increase of C, $\mathrm{Ni} \& \mathrm{~N}$ will lead to the $\delta$-ferrite content decrease, increase of $\mathrm{Cr}$ will lead to $\delta$-ferrite content increase, while Si \& Mn are different from the other elements, and they increase first, and then decrease.
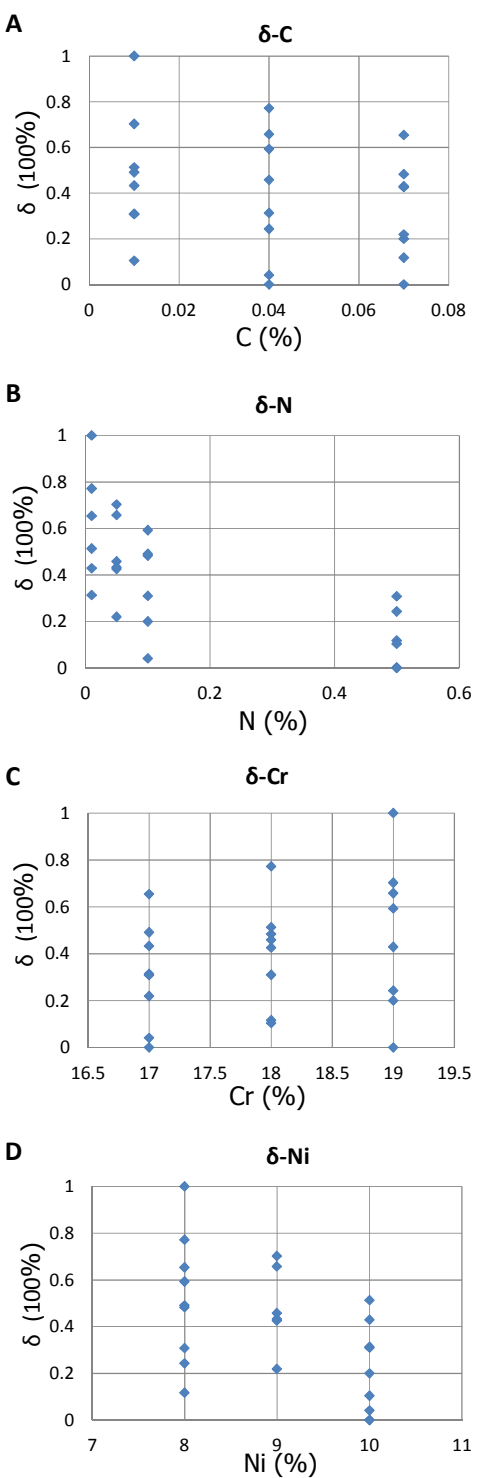

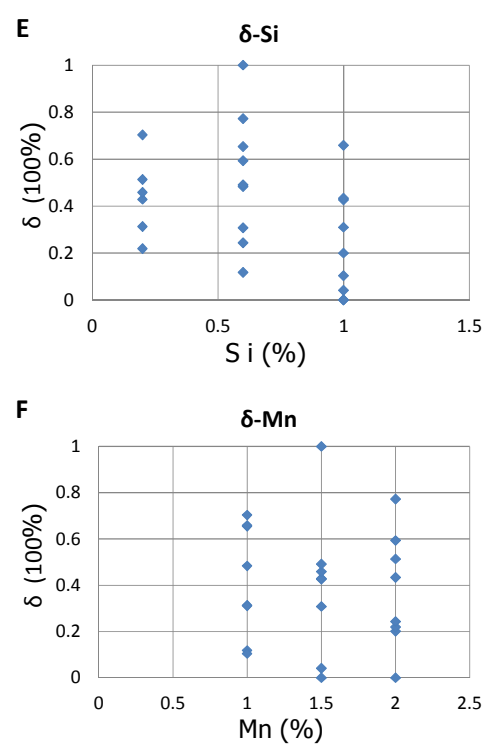

Fig. 2. Relationship between elements and $\delta$-ferrite content

\section{B. Verification Evaluation Results}

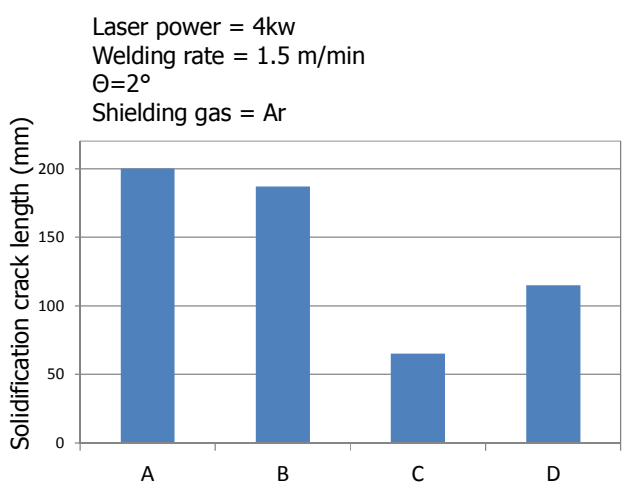

Fig. 3. Average crack length of various weld parameters

Fig. 3 shows fan-shaped laser beam welding method evaluation result, average weld crack length of different materials. From the result, there is an obvious tendencies we can get, although the difference of $\mathrm{A}$ and $\mathrm{B}$ is slight, the result shows $\mathrm{A}$ is easier to crack than $\mathrm{B}$, meanwhile $\mathrm{A}$ and $\mathrm{B}$ are easier to crack than $\mathrm{C}$, as well as D.

\section{DISCUSSION}

The alloying elements of stainless steel can be divided into ferrite former elements and austenite former elements. Such as $\mathrm{Ni}, \mathrm{Mn}, \mathrm{Co}, \mathrm{C}, \mathrm{N}, \mathrm{Cu}$, etc. are austenite former elements [2], while $\mathrm{Cr}, \mathrm{Mo}, \mathrm{S}, \mathrm{Al}, \mathrm{V}, \mathrm{W}, \mathrm{Nb}, \mathrm{Ti}$, etc. are ferrite former elements [3]. The contents of alloying elements will directly affect the solidification mode, thereby affect the welding properties of materials.

$\mathrm{Ni}$ is austenite former element, and it can expand the austenite phase region. According to the austenitizing strength of the other elements [4], we can get nickel equivalent base on Schaeffler formula [5] or Delong formula [6]. Chromium is ferrite former element, it will reduce the austenite phase region
[7-9], similarly, we also can get Chromium equivalent base on Delong formula.

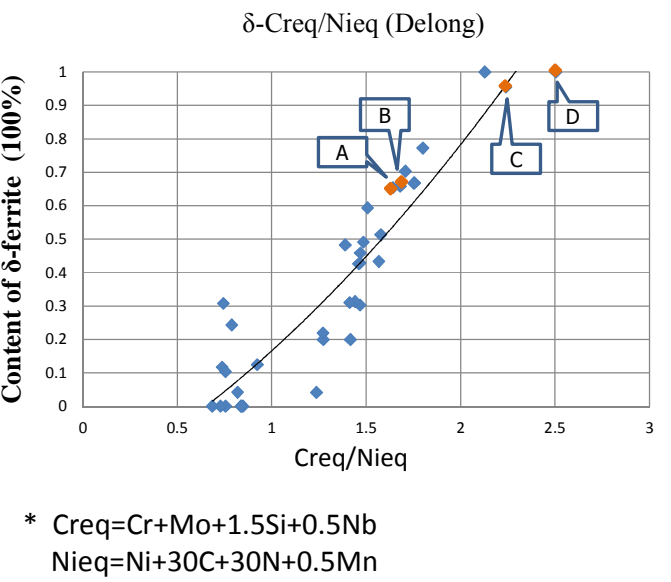

Fig. 4. Relationship between $\delta$-ferrite content and Creq /Nieq

Fig. 4 shows the relationship between $\delta$-ferrite content and Creq/Nieq of GB-SUS304 simulation results. From the result we can find that with the increase of Creq/Nieq, the content of $\delta$-ferrite will also increase. We can find that the materials from company A, B, C and D are also follow this rule.

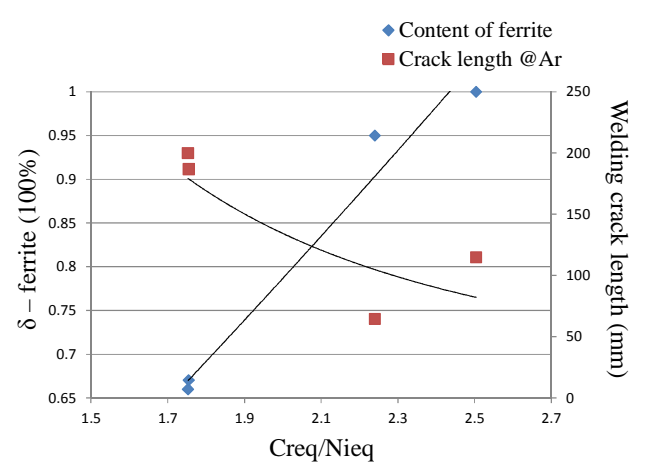

Fig. 5. Relationship between $\delta$-ferrite content, welding crack length and Creq /Nieq

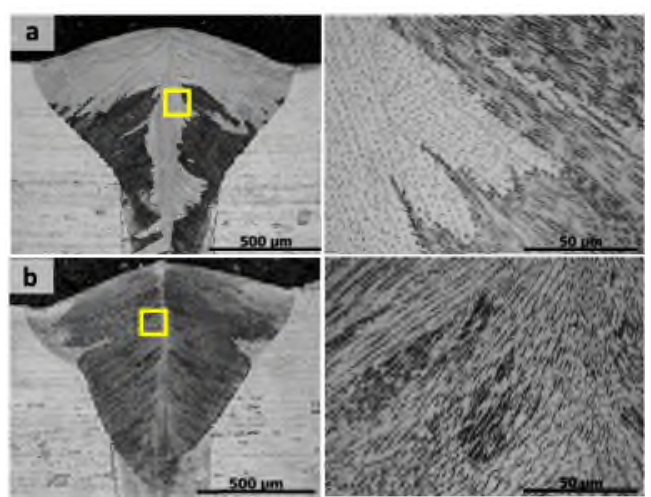

Fig. 6. Microstructure of the welding part; a. welding part with crack, b. welding part with no crack.

From the result of average crack length of different materials from company A, B, C and D (Fig. 5), we also can find that with the increase of the amount of $\delta$-ferrite, the crack 
length will decrease. Because the $\delta$-ferrite has high solubility to impurity elements, meanwhile, the crack is hard to propagation in the ferrite - austenite boundarys. Fig. 6 shows the microstructures of welding part, Fig. 6(a) is welding part with crack, Fig. 6(b) is welding part with no crack. From the enlargement of the weld joint we can find that there is a huge difference between crack welding part and no crack welding part. The grain orientation of the welding joint center part of crack welding part is consistent in a large area and the grain size is coarse. While no crack welding part is different, the austenite grain size is small, and there is only very small part in the same orientation, that's because $\delta$-ferrite was precipitated during solidification process, and the ferrites disturb the continuity of the austenite. While in crack welding part, there is no $\delta$-ferrite, therefore the austenite grows large. Therefore, $3-8 \% \quad \delta$-ferrite will significantly reduce the sensitivity of the weld crack [10].

The simulation software we used in this research can't define cooling rate, our simulation results are based on equilibrium state solidification process, while in actual rapid cooling and solidification speed, the $\delta$-ferrite content is much less than the simulation results, but we can still use this simulation results, because the the crack sensitivity trend from simulation results agree with the experimental results, we can still select the appropriate material according to this crack sensitivity trend.

Our simulation results showed that $\mathrm{C}, \mathrm{Ni} \& \mathrm{~N}$ will lead to $\delta$-ferrite content decrease, $\mathrm{Cr}$ will lead to $\delta$-ferrite content increase, while $\mathrm{Si} \& \mathrm{Mn}$ showed different from the other elements, and they increased first, then decreased. If we hope to a good material, we must control the chemical composition like this: lower $\mathrm{C}, \mathrm{Ni}$, and $\mathrm{N}$, higher $\mathrm{Cr}$, and suitable $\mathrm{Mn}$ and Si.

\section{CONCLUSIONS}

1) Increase of $\mathrm{C}, \mathrm{Ni} \& \mathrm{~N}$ will lead to $\delta$-ferrite content decreasing;

2) Increase of $\mathrm{Cr}$ will lead to $\delta$-ferrite content increasing;

3) Si \& Mn show different from the other elements, with increasing of Si \& Mn content, $\delta$-ferrite increases first and then decreases;

4) With the increase of Creq/Nieq, the content of $\delta$-ferrite will also increase, and the crack length will decrease.

\section{REFERENCES}

[1] X.J. Luo, E.J. Ashida, et al., Study on Solidification cracking Susceptibility test for Laser Beam Welding of Stainless Steels. Summary of the welding National Conference. 68th edition. 2001.

[2] W. Yu, Thermally aged cast stainless steel in water coolant system nuclear power plant, Xi'an, Xi`an Tech. University, 2008.

[3] C. Hong, "Design and Property Research of New Low-Nickel Duplex Stainless Steels Based on the d-Electron Alloy Theory", Shanghai: Rare Met. Mater. Eng. vol. 39, no. z1, 2010.

[4] X. Xi, Research and development of low nickel austenitic stainless steel for casting of curtain wall connectors, Jiangsu: Jiangsu University, 2011.

[5] A.L. Schaeffler. "Constitution diagram of stainless steel weld metal". Met. Prog. vol. 56, no. 6, pp. 680-688, 1949.
[6] W.T. Delong. "Ferrite in austenitic stainless metal". Weld. J. vol. 53, no. 7, pp. 273-286, 1974.

[7] Jernkontoret Corporation. A guide to the solidification of steels. Stockholm: Ljungberg Tryckeri AB, 1977, pp. 156-160.

[8] T. Takalo, N. Suutala and T. Moisio. "Austenitic solidification mode in austenitic stainless steel welds". Metallurg. Trans. A, vol. 10, no. 8, pp. 1173-1181, 1979.

[9] K. Rajasekhar, C.S. Harendranath, R. Raman and S.D. Kulkarni. "Microstructural evolution during solidification of austenitic stainless weld metals: a color metallographic and electron microprobe analysis study". Mater. Charact. vol. 38, no. 2, pp. 53-65, 1997.

[10] Z.H. Ji. "Effect of ferrite content on welding properties of austenitic stainless steel”. China Sp. Equip. Saf. vol. 28, no. 12, pp. 39-41, 1997. 